\title{
Microstructural Evolution during Laser Processing of Titanium Alloy
}

\author{
Stephen A. Akinlabi ${ }^{1, a^{*}}$ and Esther T. Akinlabi ${ }^{2, b}$ \\ ${ }^{1}$ Department of Mechanical and Industrial Engineering Technology, \\ University of Johannesburg, South Africa \\ 2Department of Mechanical Enginering Science, University of Johannesburg, South Africa. \\ astephenakinalbi@gmail.com, ${ }^{b}$ etakinlabi@uj.ac.za
}

Keywords: Deformation, Flame bending, Thermal stresses and X-ray diffraction

\begin{abstract}
The laser beam forming (LBF) process is a unique manufacturing process that has the potential to revolutionise rapid prototyping in the automotive and the aerospace industries. Traditionally, these industries require expensive tooling (stamping dies and presses) to form parts from sheet metal to develop prototypes for testing and evaluation. However, LBF offers an affordable non-contact and flexible rapid prototyping method for most of the manufacturing the industries. Despite these unique benefits, it is important to investigate the evolved microstructure because LBF employs high laser density to induce thermal stresses in the material to create the desired deformation. The study examines the microstructural development during laser beam processing of Ti-6Al-4V alloy sheets. The Ti-6Al-4V sheets were successfully processed at two different parameters of $800 \mathrm{~W}$ and $1000 \mathrm{~W}$, and further microstructurally characterised through the optical microscopy. The results show that the micrograph of the parent material consists of a mixture of equiaxed and acicular alpha and beta-phases which are typical of Ti-6Al-4V. The micrograph of the sample formed at $800 \mathrm{~W}$ shows structures of globular particles of beta-phase in the alpha-phase matrix with an average grain size of about $12 \mu \mathrm{m}$. Also, there was a presence of bands of martensitic structure on the micrograph as a result of the heating from the laser beam. Similarly, the samples processed at $1000 \mathrm{~W}$ shown in the micrograph an alpha -phase and apha+beta-phase with an average grain size of about $8 \mu \mathrm{m}$ with traces of martensites.
\end{abstract}

\section{Introduction}

The word LASER is an acronym for light amplification by stimulated emission of radiation [1]. LASER is the acronym for the Light Amplification by Stimulated Emission of Radiation. Albert Einstein presented the theory of stimulated emission in 1917, and the first laser was invented in 1960. The laser forming process has its origin in flame bending for ship construction, with the earliest work on laser forming beginning in the mid-1980s [2,3]. A laser beam is an artificially generated electromagnetic radiation, called laser light when in the visible wavelength range. The unique potentials provided by lasers for various applications made researchers and other manufacturing industries to embrace and utilise these enormous benefits of lasers for engineering and research. Some of such manufacturing processes that employ the potential lasers include laser material processing, and laser additive manufacturing, etc. Laser Beam Forming (LBF) is one of such technique for material processing.

Laser beam forming (LBF) is a non-contact, flexible, thermo-mechanical process employed to improve the properties of material and change the shape of a metal sheet using thermal stresses induced by laser heat energy. LBF may be complex because of many influencing factors $[4,5]$. In particular, LBF employed for the production of sheet metal prototypes, alignment and adjustment procedures, as well as for the bending of prototypes $[6,7]$ as it is nearly free of spring back [8,9]. The LBF process has been investigated in applications involving different materials such as mild steel [6, 7, 10, 11], stainless steels [12, 13], aluminium and its alloys [7, 14] titanium and its alloys $[6,15]$, and fibre metal laminates [16].

Titanium alloy is an important aerospace material because of its existing properties that include: 
high specific strength, stiffness, toughness and low coefficient of thermal expansion [17]. Titanium alloy, Ti-6Al-4V, is the most widely produced and the most commonly used titanium alloy in the aerospace industry [18]. The reason for this is that Ti6Al4V possesses excellent properties which include: high-strength-to-weight ratio, high-temperature strength, and good corrosion resistance. $\mathrm{Wu}$ et al. [19] investigated the effect of laser power, scanning speed, powder flow rate and gas flow rate on the microstructure of laser deposited Ti-6Al-4V. The investigation revealed that Ti-6Al-4V are susceptible to forming columnar grain structure which is found to increase with an increase in the laser power. Imran et al. [20] investigated the effect of laser power, scanning speed, powder mass flow rate and spot size on the characteristics of the deposited layer and found a very strong correlation between the process parameters and the deposition process.

A typical schematic is shown in Fig. 1. This is a non-contact and novel manufacturing technique employed to deform metallic plates and sheets material to produce bending and curvatures.

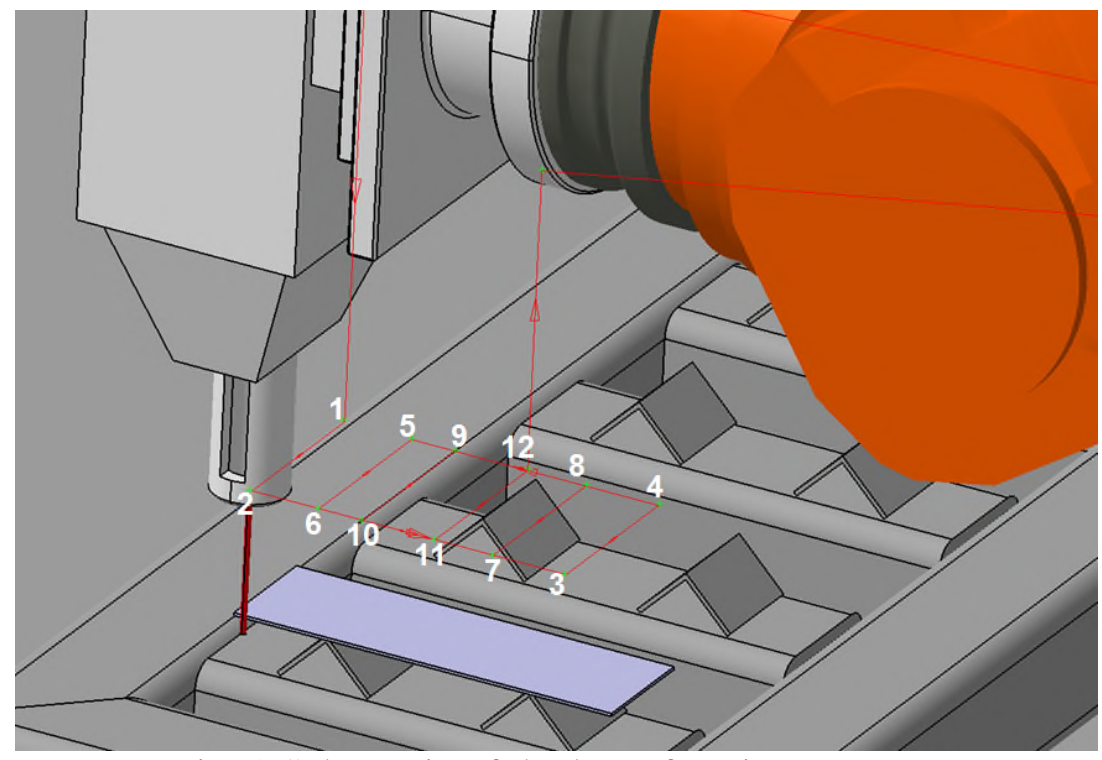

Fig. 1 Schematic of the laser forming process.

The deformation of the plate material is achieved by irradiating the surface of the plate with the laser beam, whereby developing temperature gradient through the thickness of the material inducing stresses which are the result of the different thermal expansion of the adjacent layers of the material. During the initial heating, the expansion at the top surface is more than the bottom, whereby creating a bending moment that generates compressive strain at the heating surface and tensile strain at the bottom surface. As the heating continues, the bending moment increases and plastic strains are produced as the thermally induce stress exceeds the temperature dependent yield stress of the material.

\section{Experimental Methodology}

A rectangular test piece of Ti-6Al-4V alloy, with a sample size of $90 \mathrm{~mm}$ x $30 \mathrm{~mm}$ x $1 \mathrm{~mm}$ was processed with a $4.4 \mathrm{~kW} \mathrm{Nd}$ : YAG laser at the Council for Science and Industrial Research National Laser Centre (CSIR-NLC). The experimental setup at Nation Laser Centre, CSIR is shown in Fig. 2. The experiments were conducted with two sets of process parameters presented in Table 1. 


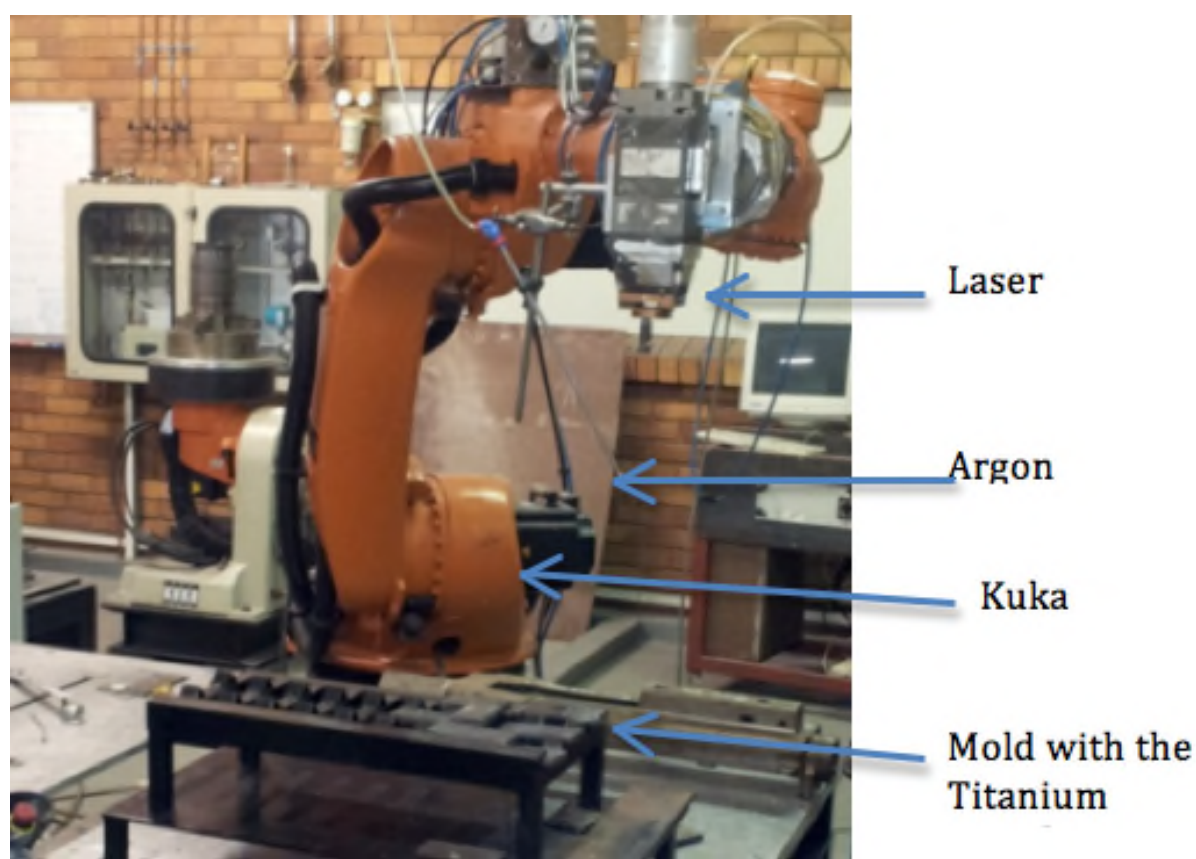

Fig. 2 Experimental set at the National Laser Centre at CSIR, Pretoria.

Table 1. Summary Process Parameters.

\begin{tabular}{|l|l|r|r|}
\hline S/N & Parameters & $\mathbf{1}$ & $\mathbf{2}$ \\
\hline 1 & Laser Power, P $(\mathrm{W})$ & 800 & 1000 \\
\hline 2 & Beam Diameter, BD $(\mathrm{mm})$ & 14 & 16 \\
\hline 3 & Scan Velocity, V $(\mathrm{mm} / \mathrm{s})$ & 0.05 & 0.07 \\
\hline 4 & Number of Tracks, N & 5 & 7 \\
\hline 5 & Argon flow rate & \multicolumn{2}{|c|}{15} \\
\hline
\end{tabular}

The parent material and processed samples were characterised through optical microscopy and microhardness. Both sectioned samples of the parent and treated Ti-6Al-4Vwere prepared through the metallographic method based on the ASTM Standard E3-01, mounted in hot poly fast resin, ground and polished. The prepared, polished samples were etched in the Kroll's reagent to reveal its microstructure. The etched samples were observed under the optical microscope.

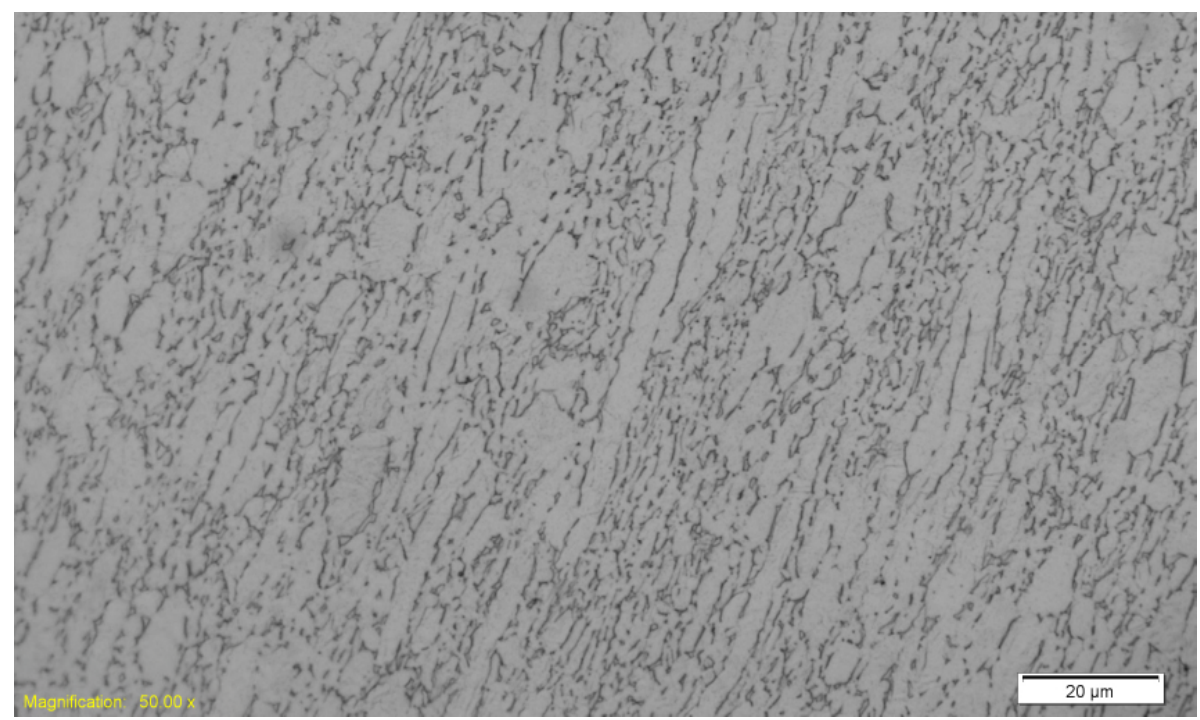

Fig. 3 Micrograph of the parent material of Ti-6Al-4V sheet. 


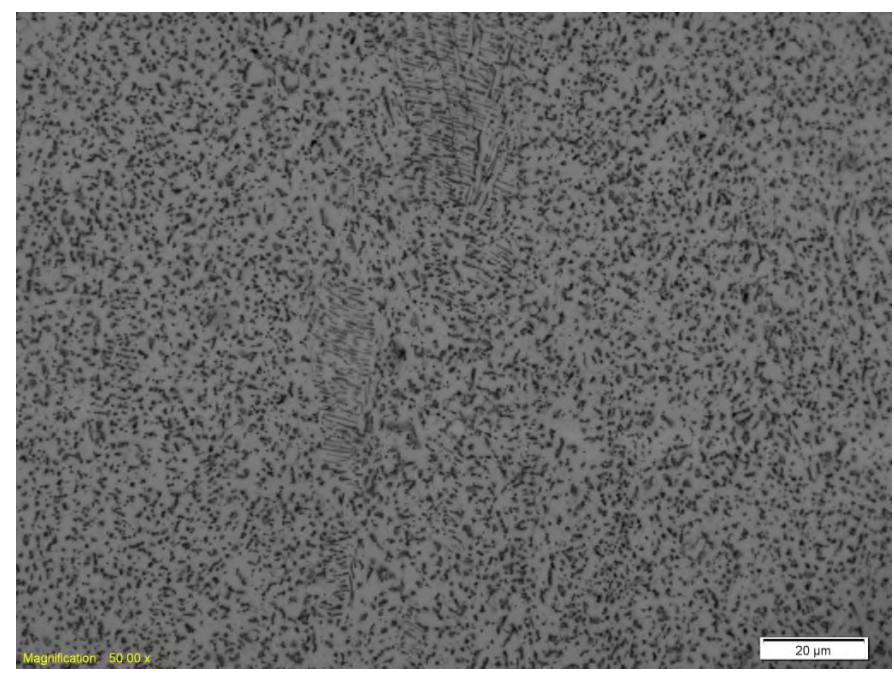

(a)

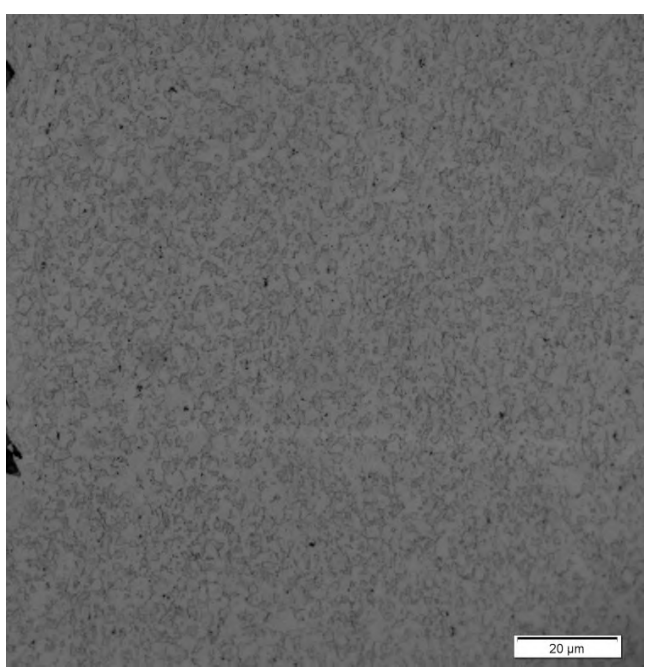

(b)

Fig. 4 (a) and (b): Processed Ti-6Al-4V micrographs at laser power of (a) $800 \mathrm{~W}$ and (b) $1000 \mathrm{~W}$.

\section{Results and Discussion}

Microstructural Evaluation. The micrographs of the parent material in presented in Fig. 3, while the two sets of the processed Ti-6Al-4V samples are shown in Fig. 4 and five respectively. The micrograph of the Ti-6Al-4V parent material is characterised with a mixture of alpha and beta phases and in particular with mixture of equiaxed and acicular alpha phases. The micrographs of the Ti-6Al-4V alloy processed at a laser power of $800 \mathrm{~W}$ also show a structure of globular particles of beta-phase in the matrix of alpha-phase. The grain structures are more crystallized when compared with the parent material, this attributed to the energy input for the processing. Also, there was a presence of a band of martensitic structure on the micrograph as a result of the heating from the laser beam because the laser beam diameter is smaller than the sample processed at a laser power of $1000 \mathrm{~W}$.

This is an indication of extreme temperature that is not always desirable for load bearing applications because the structure is often hard and brittle. Similarly, the micrographs of the Ti-6Al$4 \mathrm{~V}$ samples processed at a laser power of $1000 \mathrm{~W}$ show an alpha-phase and apha+beta-phase with an average grain size of $8.24 \mu \mathrm{m}$. There was also the band of traces of martensite even though not significant. This implies that the process Ti-6Al-4V alloy is probably at the threshold of being hard and brittle which may compromise its structural integrity regarding load-bearing applications.

Grain Size Measurement. The summary of the grain sizes of the parent material and the process Ti-6Al-4V measured are presented in Table 2.

Table 2. Measured Grain Sizes for Parent Material and Processed Ti-6Al-4V Sheets.

\begin{tabular}{|c|c|c|c|}
\hline No. & $\begin{array}{c}\text { Parent } \\
\text { Material }\end{array}$ & $\begin{array}{c}\text { Ti-6Al-4V formed } \\
\text { at 800 W }\end{array}$ & $\begin{array}{c}\text { Ti-6Al-4V formed } \\
\text { at 1000 W }\end{array}$ \\
\hline \multicolumn{4}{|c|}{ Measured Grain Sizes $(\boldsymbol{\mu m})$} \\
\hline 1 & 41.2 & 12.4 & 7.9 \\
\hline 2 & 39.7 & 11.7 & 8.5 \\
\hline 3 & 38.2 & 11.5 & 8.9 \\
\hline 4 & 41.1 & 11.9 & 8.1 \\
\hline 5 & 41.9 & 12.2 & 7.8 \\
\hline Average & $\mathbf{4 0 . 4 2}$ & 11.94 & 8.24 \\
\hline
\end{tabular}

The measurement of the grain sizes for the parent material has an average size of about $40 \mu \mathrm{m}$ but by the application of the laser beam for processing, the Ti-6Al-4V further recrystallizes the grains. The Ti-6Al-4V processed at a laser power of $800 \mathrm{~W}$ and $1000 \mathrm{~W}$ has average grain sizes of 
about $12 \mu \mathrm{m}$ and $8 \mu \mathrm{m}$ respectively. The significant change in the grain sizes of the processed Ti$6 \mathrm{Al}-4 \mathrm{~V}$ alloy sheet is attributed to the dynamic recrystallization during to the processing laser heat. This is the phenomena behind the deformation of the sheet into the desired shape and geometry. Also, it was established from this study that high-energy input promotes dynamic recrystallization. However, extreme heat on materials for targeted applications such as load bearing applications may be undesirable. Hence, such heat input must be monitored and controlled for the benefit of the process.

Microhardness Profile. The Vickers microhardness profile for both the parent material and the processed Ti-6Al-4V alloy sheets is shown in Fig. 5. All the microhardness profile show a very close correlation including the parent materials; this is a strange phenomenon because, considering the heat from the laser processing, it is expected that the Vickers microhardness values for the two sets of processed Ti-6Al-4V alloy sheet be better enhanced that the parent material. This occurrence may an isolated case considering the results of micrograph and the grain sizes from the optical microscopy

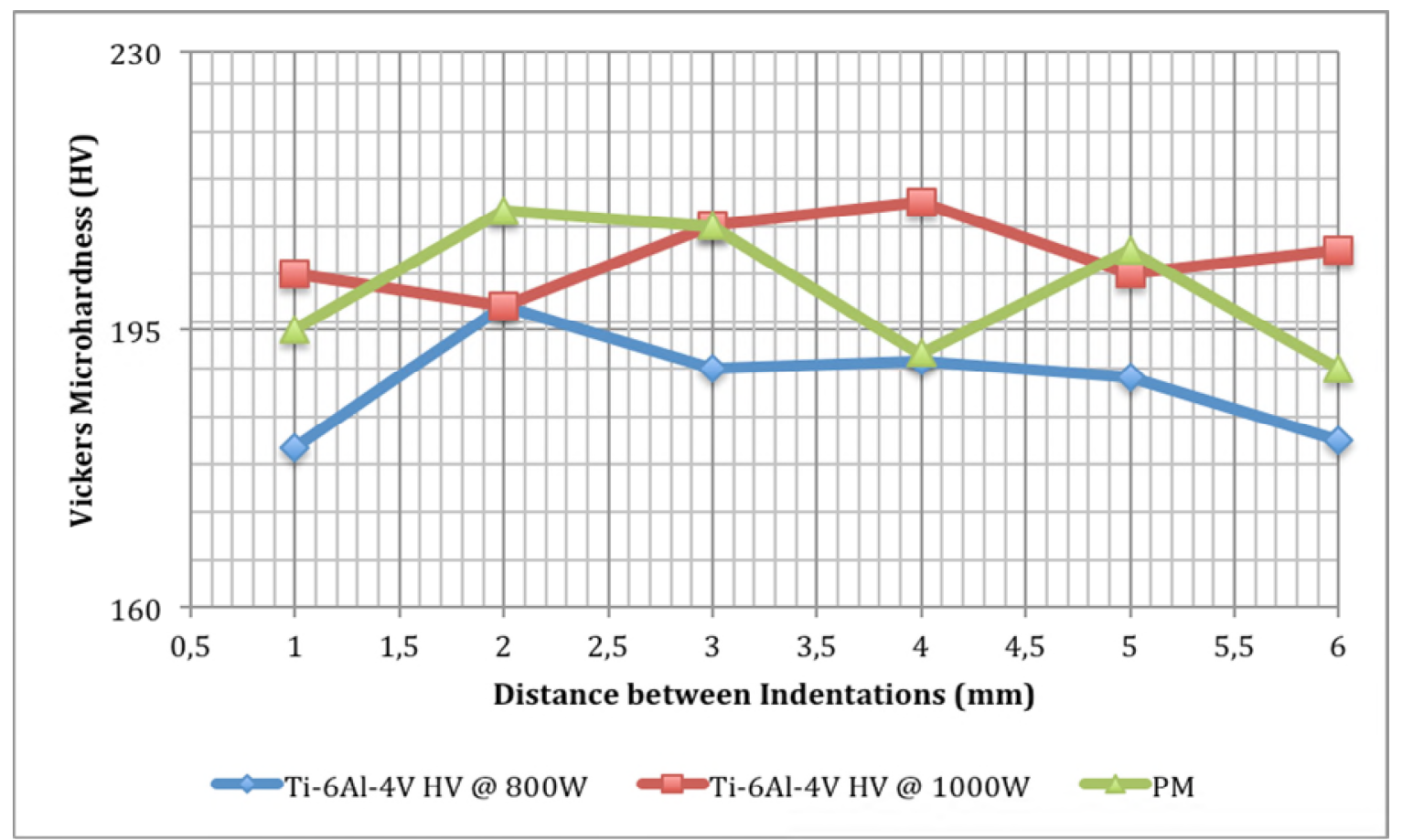

Fig. 5 Microhardness profile for the parent material and the processed Ti-6Al-4V.

\section{Conclusions}

The processing of the Ti-6Al-4V alloy sheets was successfully conducted using $4.4 \mathrm{~kW} \mathrm{Nd:} \mathrm{YAG}$ laser. Two sets of processing parameters were employed in the treatment of the alloy Ti-6Al-4V sheet. The results show that the micrographs of the parent material were made up of equiaxed and acicular grains. The micrograph of the Ti-6Al-4V alloy processed at $800 \mathrm{~W}$ and $1000 \mathrm{~W}$ show structures of globular particles of beta-phases in the alpha-phase matrix with an average grain size of about $12 \mu \mathrm{m}$ and $8 \mu \mathrm{m}$. Also, a band of martensitic structures were observed in both micrographs of processed Ti-6Al-4V, this is an indication of a hard and brittle structure, which is undesirable for load carrying applications. Such hard and brittle materials only find limited applications as ceramics, insulators and conductors, etc. Lastly, the Vickers microhardness values of both parent and process Ti-6Al-4V show some correlation.

\section{Acknowledgement}

The authors recognise the support of the Internationalization Division of the University of Johannesburg. 


\section{References}

[1] C. L. Yau, K. C. Chan, W. B. Lee, Laser bending of leadframe materials, J. Mater. Proc. Tech. 82 (1998) 117-121.

[2] E. Kannatey-Asibu. Principle of laser materials processing. John Wiley \& sons, Inc., New York, N.Y., 2009.

[3] Sheet metal forming, Available: http: //www.answers.com/topic/sheetmetalforming, (2012).

[4] Anisotropy, Available: http://en.wikipedia.org/wiki/Anisotropy, (2015).

[5] C. Thompson, M. Pridham. Material property changes associated with laser forming of mild steel Sample, J. Mater. Proc. Tech. 118 (2001) 40-44.

[6] M. Marya, G. R. Edwards. The Laser Forming of Titanium Alloys, 5th International Conference on Trends in Welding Research, Georgia. USA. ASM International, (1998), pp. 1-6.

[7] Y. Shi, Z. Yao, H. Shen, J. Hu. Research on the mechanisms of laser forming for the metal plates, Int. J. Mach. Tool. Manuf. 46 (2006) 1689-1697.

[8] Prominent Manufacturing Process, 2012, [online]. Available: http://www.brighthub.com/engineering/mechanical/articles/915.aspx, [Accessed May 2015].

[9] Manufacturing processes: Metal forming, 2012, [online]. Available: http://www.tech.plym.ac.uk/sme/mfrg315/metform1.htm, [Accessed May 18, 2013].

[10] S. Mehdi, M. Farzin. A study on laser bending of tailor machined blanks with various irradiating schemes. J. Mater. Proc. Tech. 214(1) (2014) 112-122.

[11] S. A. Akinlabi, T. Marwala, E. T. Akinlabi, M. Shukla. Effect of Scan Velocity on Resulting Curvatures during Laser Beam Bending of AISI 1008 Steel Plate, J. Adv. Mater. Res. 299-300 (2011) 1151-1156.

[12] K. Maji, D. K. Pratihar, A. K. Nath. Laser forming of a dome shaped surface: Experimental investigations, statistical analysis and neural network modelling. Opt. Laser. Eng. 53 (2014) 31-42.

[13] M. J. Dutta, A. K. Nath, I. Manna, Studies on Laser bending of stainless steel, Mater. Sci. Eng. A 385 (2004) 113-122.

[14] W. Li, Y. L. Yao, Laser forming with constant Line Energy, Int. J. Adv. Manuf. Tech. 17 (2001) 196-203.

[15] D. F. Walczyk, S. Vittal, Bending of Titanium Sheet using Laser forming, J. Manuf. Proc. 2/4 (2000) 258-269.

[16] S. P. Edwardson, P. French, K. G. Dearden, K. G. Watkins, W. J. Cantwell. Laser forming of fibre metal laminates, Laser. Eng. 15 (2005) 233-255.

[17] M. N. Ahsana, A. J. Pinkerton, R. J. Moatb, J. Shackleton, A comparative study of laser direct metal deposition characteristics using gas and plasma-atomized Ti-6Al-4V powders, Mater. Sci. Eng. A 528 (2011) 7648-7657.

[18] A. G. Ermachenko, R. Y. A. Lutfullin, R. R. Mulyukov. Advanced technologies of processing titanium alloys and their applications in industry. Rev. Adv. Mater. Sci. 29 (2011) 68-82.

[19] X. Wu, J. Liang J, Mei, C. Mitchell, P. S. Goodwin, W. Voice. Microstructures of laser deposited Ti-6Al-4V. Mater. Des. 25(2) (2004) 137-44.

[20] M. K. Imran, S. H. Masood, M. Brandt. Influence of process parameters in the direct metal deposition of h13 tool steel on copper alloy substrate. Proceedings of the world congress on engineering 2010, WCE 2010, June 30-July 2, London, UK, 3; (2010), pp. 2213-2218. 